\title{
An Overview of Vertical Handoff Decision Making Algorithms
}

\author{
A. Bhuvaneswari \\ Department of Computer Science, Cauvery College for Women, Trichy, Tamil Nadu, India. \\ Dr. E. George Dharma Prakash Raj \\ Department of Computer Science, Bharathidasan University, Trichy, Tamil Nadu, India.
}

\begin{abstract}
Uncontrollable development of wireless and mobile communication technology aims to provide the seamless continuous connection to access various wireless technologies and to have connection with the best network which provides the best quality of service (QoS). Each application requires different QoS, so the network selection may vary accordingly. To achieve this goal and to select the best network for a mobile terminal when moving from one network to another, it is necessary to have a good decision making algorithm which decides the best network for a specific application that the user needs based on QoS parameter. This paper presents an overview of handoff types, handoff process, and classification of vertical handoff, parameters required, existing work and the comparison table.
\end{abstract}

Index Terms - Quality of Service (QoS), Vertical Handoff (VHO), Horizontal Handoff (HHO), Multi Attribute Decision Making (MADM), Wi-Fi, Wi-Max, GPRS, CDMA

\section{INTRODUCTION}

Recent years mobile terminals (MT) are equipped with multiple interfaces and can access a wide range of applications provided by multiple wireless networks in an Always Best Connected(ABC) mode. To access the communication services anytime, anywhere with best Quality of Service (QoS) at minimum cost heterogeneous wireless communication system is a best solution. Numerous wireless networks such as Bluetooth, Wi-Fi, Wi-Max, GPRS and CDMA have been evolved. Each network has been developed for specific purpose with different features which is tabulated in Table I.

Heterogeneous Wireless Networks has different access technologies, overlapping and coverage, and network architecture, protocols for transport, routing and mobility management.

Also different operator offers different service demands from mobile users (voice, video, multimedia, text etc.) in the market.

Because of these variations, when the mobile user moves there is a need to handover the communication channel from one network to another by considering its features and also the user requirements. Channel handover between two different networks has been done by vertical handoff. During handover there is a need to decide and choose the best network as mentioned above. So the Vertical Handoff Decision Making is an important research issue.

The rest of the paper is organized as follows: Section II explains types of handoffs and three steps of vertical handoff process. Section III depicts the classification of VHO. Section IV discusses the various static and dynamic parameters which should be considered during vertical handoff decision making. Section $\mathrm{V}$ describes the existing algorithms to make vertical handoff decision. Section VI provides some research issues. Section VII presents the comparison table based on analysis of existing vertical handoff decision algorithms. Finally, section VIII concludes the survey.

\section{TYPES OF HANDOFF}

Handoff can be classified into two types [1], i.e., Horizontal Handoff(Symmetric), which means the handoff within the same wireless access network technology. Vertical Handoff(Asymmetric) means handoff among heterogeneous wireless access network technology. Parameters of Horizontal and Vertical Handovers are also varying which is tabulated in Table II. Since VHO is an asymmetric process, the MT(Mobile Terminal) moves between two different networks with different characteristics. So, it is necessary to select the best network which provides high performance. The VHO operation should provide a minimum overhead, authentication of the mobile users and the connection should be maintained to minimize the packet loss and transfer delay.

Table I 3G-4G ACCESS TECHNOLOGIES [21]

\begin{tabular}{|l|l|l|l|}
\hline Factors & Wi-Fi & Wi-Max & UMTS \\
\hline Data Rate & $54 \mathrm{Mbps}$ & $\begin{array}{l}\text { DL=70 Mbps } \\
\text { UL=70 Mbps }\end{array}$ & $\begin{array}{l}\text { DL=2Mbps } \\
\text { UL=2Mbps }\end{array}$ \\
\hline Bandwidth & $20 \mathrm{MHz}$ & $5-6 \mathrm{GHz}$ & $5 \mathrm{MHz}$ \\
\hline $\begin{array}{l}\text { Multiple } \\
\text { Access }\end{array}$ & $\begin{array}{l}\text { CSMA/ } \\
\text { CA }\end{array}$ & $\begin{array}{l}\text { OFDM/ } \\
\text { OFDMA }\end{array}$ & CDMA \\
\hline Coverage & $300 \mathrm{~m}$ & $16 \mathrm{Km}$ & Wider \\
\hline Mobility & Low & Medium & High \\
\hline
\end{tabular}


TableII VERTICAL AND HORIZONTAL HANDOVERS [21]

\begin{tabular}{lll}
\hline \multicolumn{1}{c}{ Parameters } & $\begin{array}{l}\text { Horizontal } \\
\text { Handover }\end{array}$ & $\begin{array}{l}\text { Vertical } \\
\text { Handover }\end{array}$ \\
\hline Access Technology & Not Changed & Changed \\
QoS Parameters & Not Changed & $\begin{array}{l}\text { May be } \\
\text { Changed }\end{array}$ \\
IP Address & Changed & Changed \\
Network Interface & Not Changed & May be \\
& hanged & Core than One \\
Network Connection & Single & $\begin{array}{l}\text { Connection } \\
\end{array}$ \\
\end{tabular}

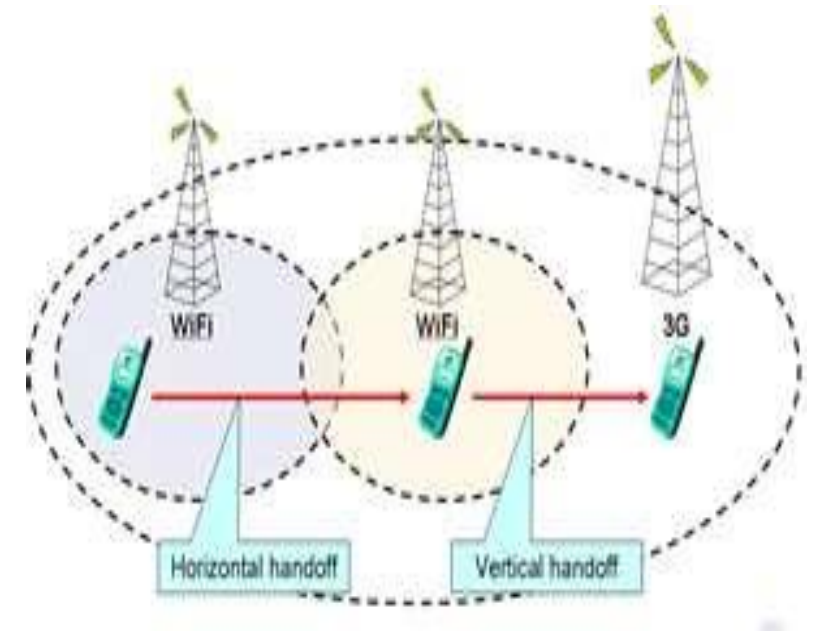

Figure 1 Handoff Types

VHO PROCESS:

The vertical handoff process can be divided into three main steps [2], [3], namely handoff initiation, handoff decision, and handoff execution.

\section{i)Handoff Initiation Phase:}

In order to trigger the handoff event, information to be collected about the network from different layers likes Link Layer, Transport Layer and Application Layer. These layers provide the information such as RSS, bandwidth, link speed, throughput, jitter, cost, power, user preferences and network subscription etc. Based on this information handoff will be initiated in an appropriate time.

\section{ii)Handoff Decision Phase:}

The mobile device decides whether the connection to be continued with current network or to be switched over to another one. The decision may depend on various parameters which have been collected during handoff initiation phase.
iii)Handoff Execution Phase:

Existing connections need to be re-routed to the new network in a seamless manner. This phase also includes the authentication and authorization, and the transfer of user's context information.

\section{CLASSIFICATION OF VHO}

Vertical Handoff can be classified in to four types based up on its direction, process, control and decision [19]:

\section{i) Upward and Downward Handoffs:}

In Vertical Handoff, if the mobile switches from the network with a small coverage to a network of larger coverage, it is termed as upward handoff. On the other hand, a downward handoff occurs in the reverse direction, i.e. from a network of larger coverage to a network of smaller coverage.

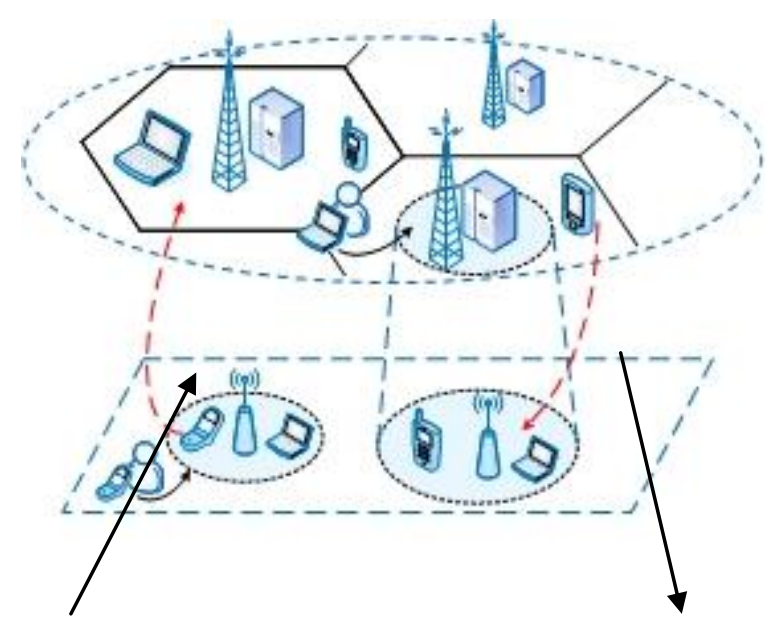

Figure 2 Upward and Downward Handoffs

Upward Handoff Downward Handoff

\section{ii) Hard and Soft handoffs:}

When the mobile node switches to the target network only after the disconnection from current network is called as hard handoff or break before make. On the other hand, in soft handover a mobile node maintains the connection with the previous base station till its association with the new base station is completed. This process is also termed as make before break.
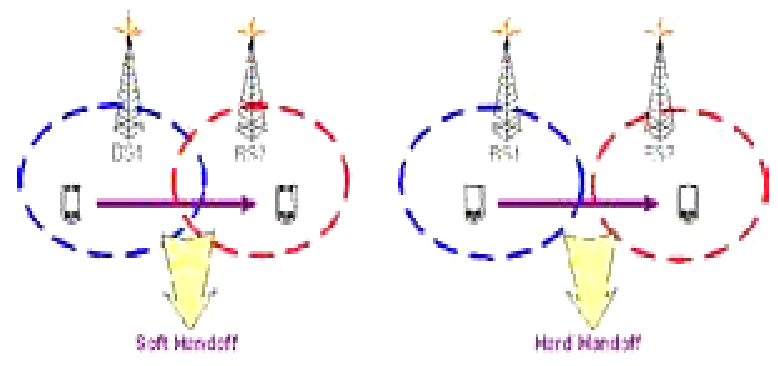

Figure 3 Hard and Soft Handovers Soft Handoff 


\section{iii) Imperative and Alternative handoffs:}

When there is loss of signal strength an imperative handoff occurs. For imperative handoff the RSS is sufficient to be considered. On the other hand, an alternative vertical handoff is initiated to provide the user with better performance. For alternative handoffs several other network parameters such as available bandwidth, supported velocity and cost of the network are to be considered in addition to the device parameters such as quality of service demanded by the application and user preference.

\section{iv) Mobile Controlled and Network Controlled Handoffs:}

Vertical handoffs can further be classified based on who controls the handoff decision. If mobile node controls the handoff decision, it is termed as Mobile controlled handoff (MCHO). In Network controlled Handoff (NCHO) networks control the handoff decision. The handoff decision control is shared between the network and mobile in case of Mobile controlled Network Assisted (MCNA) and Network Controlled Mobile Assisted handoffs (NCMA). MCNA handoffs are more suitable because only mobile nodes have the knowledge about the network interfaces they are equipped with and user preferences can be taken into consideration.

\section{IV.VHO DECISION MAKING PARAMETERS}

In heterogeneous networks, Vertical handoffs can be initiated for convenience rather than connectivity reasons. A decision algorithm gives a better performance when several parameters are considered, more so when a combination of static and dynamic parameters are considered. But the trade off is with the increase in decision time and complexity of the algorithm. The decision may depend on various groups of parameters such as [4],

- Network- Related Parameters - Bandwidth, Latency, RSS, SIR, Cost, Security etc.

- Terminal Related Parameters - Velocity, Battery power, Location Information etc.

- User-Related Parameters - user profile and preferences

- Service Related Parameters - service capacities, QoS etc.

These parameters are also categorize as [5][6], STATIC - Cost, Security, Power Consumption DYNAMIC - Bandwidth, Latency, Received Signal Strength, Throughput (data rate), Bit Error Rate, Reliability, User Preferences, Network Load Balancing, Velocity.

\section{i)Bandwidth}

Bandwidth is a measure of the width of a range of frequencies. Higher the bandwidth, lower the call dropping and call blocking probability.

\section{ii)Handoff Latency}

The time elapses between the last packet received via the old access router and the arrival of the first packet along the new access router after a handoff. This is known as handoff latency. Handoff Latency affects the QoS and it is essential to consider handoff latency while designing any handoff technique.

\section{iii)Power Consumption}

During handoff, frequent interface activation can cause considerable battery drainage. It is also important to incorporate power consumption factor during handoff decision.

\section{iv)Network Cost}

A multi criteria algorithm for handoff should also consider the network cost factor. Different charging policies are followed for different type of traffic. So that in some situation cost should also be consider as a factor for decision making.

\section{v)User Preferences}

Based on the application requirements like (real time, non-real time), service types (Voice, data, video), Quality of service etc. the user may prefer different network according to the network performance which is the important benefit of heterogeneous networks.

\section{vi)Network Throughput}

Network throughput refers to the average data rate of successful data or message delivery over a specific communications link. Handover to the network which has higher throughput is desirable.

\section{vii)Network Load Balancing}

Network load is to be considered during effective handoff. It is important to balance the network load to avoid deterioration in quality of services.

\section{viii)Network Security}

In a wireless environment, the security features provided in some wireless products may be weaker; to attain the highest levels of integrity, authentication, and confidentiality, network security features should be embedded in the handoff policies.

\section{ix)Received Signal strength (RSS)}

A signal must be strong enough between base station and mobile unit to maintain signal quality at receiver. The RSS should not be below a certain threshold in a network during handoff. Traditional Handoff initiation is concerned with measurement of RSS [7].

\section{$x)$ Velocity}

Velocity of the host should also be considered during handoff decision. Because of the overlaid architecture of 
heterogeneous networks, handing to the small cell area, travelling at high speeds is discouraged since a handoff back to the original network would occur very shortly afterwards [8].

A good handoff mechanism decision model should have both dynamic and non-dynamic metrics. However, it is important to consider maximum number of static and dynamic requirements during $\mathrm{VHO}$ but it is difficult to include all the metrics in a single decision model due to complexity of algorithms and conflicting issues of multiple metrics.

\section{Vertical Handoff DeCision MaKing AlgorithMS}

In this literature survey various handoff decision algorithms have been discussed. Normally, these decision algorithms can be grouped as following:

(1) Traditional (2) function-based (3) user-centric (4) Multiple attributes decision making (5) Fuzzy logic and neural networks and (6) context-aware.

Traditional handoff decision algorithm uses the received signal strength (RSS) with other parameters. The first policy-enabled handover strategy [9] proposes the cost function to select the best available network in the decision making. Optimized cost function is used to select the target network by introducing trade off between user satisfaction and network efficiency. Paper [10] mainly focuses user's monetary budget and also user's velocity and location information. To assess the quality of the connection and to model the signalling and call dropping, benefit function and penalty functions are used respectively which uses policy iteration and Q-learning algorithm to determine the optimal policy.

Multiple Attribute Decision Making (MADM) deals with the problem of choosing an alternative from a set of alternatives which are characterized in terms of their attributes. The most popular classical MADM methods are:

[11] SAW (Simple Additive Weighting): the overall score of a candidate network is determined by the weighted sum of all the attribute values. TOPSIS [13] (Technique for Order Preference by Similarity to Ideal Solution): the chosen candidate network is the one which is the closest to ideal solution and the farthest from the worst case solution. AHP [12] (Analytic Hierarchy Process): decomposes the network selection problem into several sub-problems and assigns a weight value for each sub-problem. GRA [14] (Grey Relational Analysis) is then used to rank the candidate networks and selects the one with the highest ranking.

Grey Relation Analysis for Vertical Handover Decision Schemes in Heterogeneous Wireless Networks [14] compares two vertical handover decision schemes (VHDS). Distributed handover decision scheme (DVHD) and Trusted Distributed vertical handover decision schemes (T-DVHD). AHP was used to determine the weights for the three models requiring information about the relative importance of each attribute.

Congestion-aware Proactive Vertical Handoff Decision Using Coalition Game[15] aims at maximizing the utilization of the resources available and meeting QoS requirement of users as much as possible by initiating vertical handoff. Vertical handoff with coalition game can reduce the service time and delay for handoff calls. Future work includes performance analysis of the proposed scheme for real time and non-real time services.

The Dynamic Decision Model for VHO [1] adopts a three phase approach comprising Priority phase, Normal phase and Decision phase. The Priority Phase, assign the priorities to all candidate networks. The Normal phase record the system information and user preferences. It then calculates a cost function for each candidate network. Finally, the Decision phase calculates a Score function, for each candidate network. It then select a network having the highest value of score function as "Best" network to handoff and transfer all the current transmissions to selected network if different from the current network.

A novel decision strategy [16] considers the performance of the whole system while taking VHO decisions by meeting individual needs. It ensures the high system performance by reducing the unnecessary handoffs. A time adaptive VHO decision scheme [17] make right $\mathrm{VHO}$ decisions timely through adjusting interface activating intervals based on the user's movement and the actual network performance.

Cross-layer approach for performing vertical handovers based on MIH triggers [18] is new in the domain of User Centric handover approach. Basically the information is taken from MAC layer, Transport layer and from the application layer for handoff triggering. These show the need of cross-layer design for vertical handoff decision. Also this paper consider the user preferences, that means the user may require to choose the cost effective network, or best performance network even if it is costly because of the importance of connectivity. So the user needs a dynamic hybrid approach based upon different situations.

Vertical Handoff Decision using Game Theory Approach for Multi-mode Mobile Terminals in Next Generation Wireless Networks [19] presents a vertical handoff decision algorithm for multi-mode terminals using Game Theory approach. The algorithm enables mobile users to choose optimal network based on Bayesian Nash-equilibrium point that maximizes the offered quality of service with minimum cost. It greatly reduces the handoff delay and also enables mobile user always connecting to the best network with highest utilization at best prices.

Quality Dependent Vertical Handover Decision Algorithm for Fourth Generation (4G) Heterogeneous Wireless Networks [20] proposes a vertical handoff decision function (VHDF). This method is combination of weight distribution and cost factor calculation. The network with the highest quality and lowest cost is selected as the handover target network. This method is able to maximize the user's satisfaction level by choosing the one access network.

Fuzzy Logic (FL) and Neural Networks (NN) concepts are applied to choose when and over which network to 
hand over among different available access networks. These are combined with the multiple criteria or attribute concept in order to develop advanced decision algorithms for both non-real-time and real-time applications.

\section{ANALYSIS}

Following table outlines the name of the algorithm, methods used for decision making, parameters used, advantages and its drawbacks. Out of these, the traditional and function based methods considers only the minimum number of parameters. So its performance on throughput and others may decrease while more constraints were added. User centric approach considers the user related parameters and preferences. But in some situation the network conditions and constraints should also be considered. At that time the current method may become complicated and performance may degrade. Several VHO decision algorithms prefers Multi Attribute Decision Making (MADM) algorithm because more number of parameters can be used for decision making and the problem can be decomposed for simplicity in hierarchical model. Some uses Fuzzy based decision making which is an intelligent approach but more number of fuzzy rule set should be formed. Context aware decision algorithm considers the user information, network and user device context information which is an efficient method but more constraints are there. Apart from these many other methods like cross layer approach, game theory and genetic algorithms are also used for decision making. Normally all of these algorithms use both static and dynamic parameters for decision making. But only few papers consider call dropping rate as a decision parameter.

\section{RESEARCH ISSUES}

Future wireless systems will be based on heterogeneous wireless access technology. In order to provide seamless services many challenging issues to be solved.

QoS Issues- Mobile terminals carrying real time and non real time traffic should be serviced with guaranteed QoS. To provide best network service several parameters to be considered.

TCP Performance Issues - When switching from low bandwidth, high data rate network to high bandwidth, low data rate network TCP performance should be considered for congestion.

Security Issues - Because of the wide coverage area when the sensitive data is transmitted it should be transferred in secured manner.

\section{CONCLUSION}

This paper presents a comprehensive survey of vertical handover decision schemes. Today's hot research area in wireless network is to find the best vertical handoff decision algorithm which meets the requirements of both user and network providers. Several methods have been proposed in the literature survey, but still there is no standard and efficient method to fulfill both user and network requirements with QoS. 
TABLE III OUTLINE TABLE OF VERTICAL HANDOFF DECISION MAKING ALGORITHMS

\begin{tabular}{|c|c|c|c|c|}
\hline Name & Method & Parameters Used & Advantages & Disadvantages \\
\hline RSS Measurement & Traditional & $\begin{array}{c}\text { RSS with } \\
\text { Threshold, Dwell } \\
\text { time, }\end{array}$ & $\begin{array}{l}\text { Reduces the handoff } \\
\text { blocking }\end{array}$ & $\begin{array}{l}\text { Low through put and } \\
\text { user preferences are not } \\
\text { considered }\end{array}$ \\
\hline Policy-enabled & Function & Cost function & $\begin{array}{l}\text { Simplify handoff } \\
\text { process, Speed up } \\
\text { handoff decision }\end{array}$ & $\begin{array}{c}\text { Increases the } \\
\text { complexity, ambiguous } \\
\text { handoff decision }\end{array}$ \\
\hline Constraint MDP & User-centric & $\begin{array}{c}\text { Connection } \\
\text { duration, delay, } \\
\text { bandwidth, cost, } \\
\text { Velocity }\end{array}$ & $\begin{array}{l}\text { Reduce call dropping, } \\
\text { monetary budget for } \\
\text { connection }\end{array}$ & $\begin{array}{l}\text { When user's velocity } \\
\text { increased call dropping } \\
\text { also increased }\end{array}$ \\
\hline Cross-layer & User Centric & User preferences & $\begin{array}{l}\text { Works well for both QoS } \\
\text { and non QoS } \\
\text { applications, reduces } \\
\text { handoff delay }\end{array}$ & $\begin{array}{l}\text { Many input from } \\
\text { different layers and user } \\
\text { for handoff trigger }\end{array}$ \\
\hline $\begin{array}{c}\text { Dynamic } \\
\text { Decision Model }\end{array}$ & User Centric & $\begin{array}{c}\text { RSS, RSST, } \\
\text { bandwidth, power, }\end{array}$ & $\begin{array}{c}\text { Simple and efficient, } \\
\text { number of handoffs } \\
\text { reduced }\end{array}$ & $\begin{array}{l}\text { Suitable for soft vertical } \\
\text { handoffs only }\end{array}$ \\
\hline Quality Dependent & User Centric & $\begin{array}{c}\text { Bandwidth, Power, } \\
\text { cost }\end{array}$ & $\begin{array}{c}\text { maximize the user's } \\
\text { satisfaction level }\end{array}$ & $\begin{array}{l}\text { Not considered the } \\
\text { network parameters }\end{array}$ \\
\hline AHP & MADM & $\begin{array}{l}\text { Bandwidth, delay, } \\
\text { Jitter, Packet Loss, } \\
\text { Cost, Security }\end{array}$ & $\begin{array}{c}\text { Reduces handoff latency } \\
\text { and Computational } \\
\text { Overhead }\end{array}$ & $\begin{array}{c}\text { RSS }<\text { threshold value is } \\
\text { not considered }\end{array}$ \\
\hline SAW & MADM & $\begin{array}{l}\text { Bandwidth, delay, } \\
\text { Jitter, Packet Loss }\end{array}$ & $\begin{array}{l}\text { Reduce processing delay } \\
\text { and trusted handover }\end{array}$ & $\begin{array}{l}\text { Minimum number of } \\
\text { parameters are } \\
\text { considered }\end{array}$ \\
\hline WPM/ MEW & MADM & $\begin{array}{l}\text { Bandwidth, Jitter, } \\
\text { delay, cost }\end{array}$ & $\begin{array}{l}\text { Reduce processing delay } \\
\text { and trusted handover }\end{array}$ & $\begin{array}{l}\text { Minimum number of } \\
\text { parameters are } \\
\text { considered }\end{array}$ \\
\hline TOPSIS & MADM & $\begin{array}{l}\text { SINR, data rate, } \\
\text { bandwidth, cost }\end{array}$ & $\begin{array}{l}\text { Excellent performance } \\
\text { against requirement of } \\
\text { traffic and user }\end{array}$ & $\begin{array}{l}\text { QoS parameters are } \\
\text { Not considered }\end{array}$ \\
\hline GRA & MADM & $\begin{array}{c}\text { Bandwidth, Jitter, } \\
\text { delay, cost }\end{array}$ & $\begin{array}{l}\text { T-DVHD reduces } \\
\text { procession delay. }\end{array}$ & $\begin{array}{l}\text { Handoff dropping rate is } \\
\text { high }\end{array}$ \\
\hline QoS Aware & Fuzzy & $\begin{array}{l}\text { Bandwidth, jitter, } \\
\text { delay, error rate }\end{array}$ & $\begin{array}{l}\text { good performance for } \\
\text { delay sensitive } \\
\text { applications }\end{array}$ & $\begin{array}{l}\text { Bandwidth performance } \\
\text { is moderate }\end{array}$ \\
\hline $\begin{array}{c}\text { Minimizing Handoff } \\
\text { using Genetic } \\
\text { Algorithm } \\
\end{array}$ & Context aware & $\begin{array}{l}\text { User, networks, and } \\
\text { user device } \\
\text { information } \\
\end{array}$ & $\begin{array}{l}\text { Fast handoff, less delay, } \\
\text { minimum handoff, } \\
\text { simple }\end{array}$ & $\begin{array}{c}\text { Multimedia traffic is not } \\
\text { considered }\end{array}$ \\
\hline Congestion-Aware & Game Theory & $\begin{array}{l}\text { Congestion on } \\
\text { network traffic }\end{array}$ & $\begin{array}{l}\text { Reduce congestion, } \\
\text { service time and delay }\end{array}$ & $\begin{array}{l}\text { Traffic type is not } \\
\text { considered. }\end{array}$ \\
\hline
\end{tabular}

AHP - Analytical Hierarchical Process, WPM - Weighted Product Model, GRA - Grey Relation Analysis TOPSIS - Technique for Order Preferences by Similarity to Ideal Solution
SAW - Simple Additive Weight

MEW - Multiplicative Exponent Weighting

MADM - Multi Attribute Decision Making 


\section{REFERENCES}

[1] "A Dynamic Decision Model for Vertical Handoffs across Heterogeneous Wireless Networks" - Pramod Goyal, and S. K. Saxena - World Academy of Science, Engineering and Technology - (2008).

[2] "An Overview on Decision Techniques for Vertical Handoffs across Wireless Heterogeneous Networks" Akhila S, Jayanthi K Murthy, Arathi R Shankar, Suthikshn Kumar, International Journal of Scientific \& Engineering Research, Volume 3, Issue 1, January(2012).

[3] "An overview of vertical handover decision strategies in heterogeneous wireless networks" -Meriem Kassar *, Brigitte Kervella, Guy Pujolle, Science Direct, January (2008).

[4] "Minimization of Number of Handoff Using Genetic Algorithm in Heterogeneous Wireless Network"Mrs.Chandralekha, Dr.Praffula Kumar Behera, nternational Journal of Latest Trends in Computing (E-ISSN: 2045-5364) 24 Volume 1, Issue 2, December 2010

[5] "Comparison between Vertical Handoff Decision Algorithms for Heterogeneous Wireless Networks", Enrique Stevens, Navarro and Vincent W.S. Wong.

[6] "Requirements of Vertical Handoff Mechanism in 4G Wireless Networks", - Mandeep Kaur Gondara1 and Dr. Sanjay Kadam2, International Journal of Wireless \& Mobile Networks (IJWMN) Vol. 3, No. 2, April 2011 DOI : 10.5121/ijwmn.2011.3202 18.

[7] "Context aware handover using active network technology", - Q. Wei, K. Farkas, C. Prehofer, P. Mendes, B. Plattner, Computer Networks 50 (15) (2006) 2855-2872.

[8] "An overview of vertical handover decision strategies in heterogeneous wireless networks", - Meriem Kassar, Brigitte Kervella, Guy Pujolle, Computer Communications $31 \quad$ (2008) 2607-2620, Elsevier,January 2008

[9] "Policy-enabled handoffs across heterogeneous wireless networks", - H. Wang, R. Katz, J. Giese, Second IEEE Workshop on Mobile Computing Systems and Applications, 1999 (Proceedings WMCSA'99), 1999, pp. 51-60.

[10] "A Constrained MDP-based Vertical Handoff Decision Algorithm for $4 \mathrm{G}$ Heterogeneous Wireless Networks" - Chi Sun . Enrique StevensNavarro · Vahid Shah-Mansouri · VincentW.S. Wong Received: 22nd December 2008 / Accepted: 10th January 2011

[11] "Vertical Handover decision schemes using SAW and WPM for Network selection in Heterogeneous Wireless Networks" - K.Savitha, Dr.C.Chandrasekar, Global Journal of Computer Science and Technology Volume 11 Issue 9 Version 1.0 May 2011

[12] "AHP and Group Decision Making for Access Network Selection in Multi-Homed Mobile Terminals", - K. Radhika, Dr. A. Venugopal Reddy, International Journal on Computer Science and Engineering (IJCSE), ISSN : 0975-3397 Vol. 3 No. 10 October 2011
[13] "An Improved TOPSIS Vertical Handoff Algorithm for Heterogeneous Wireless Networks", - Liu Shengmei, Pan su, Xu Ming-hai, 2009.

[14] "Grey Relation Analysis for Vertical Handover Decision Schemes in Heterogeneous Wireless Networks", - K. Savitha, C. Chandrasekar, European Journal of Scientific Research, ISSN 1450-216X Vol.54 No.4 (2011), pp.560-568.

[15] "Congestion-aware Proactive Vertical Handoff Decision Using Coalition Game", - S.V. Saboji, C. B. Akki, International Journal of Soft Computing and Engineering (IJSCE) ISSN: 2231-2307, Volume-1, Issue-6, January 2012

[16] "A Novel Decision Strategy of Vertical Handoff in Overlay Wireless Networks" ,- Shen,W.;Zeng,Q.-A. Fifth IEEE International Symposium on Network Computing and Applications, (2006).

[17] "A Time-Adaptive Vertical Handoff Decision Scheme in Wireless Overlay Networks", - Qingyang Song, Abbas Jamalipour, IEEE $17^{\text {th }}$, International Symposium on Personal, Ind,oor and Mobile Radio Communications, 2006.

[18] “A Cross-Layer User Centric Vertical Handover Decision Approach Based on MIH Local Triggers", Maaz Rehan, Muhammad Yousaf, Amir Qayyum, and Shahzad Malik, J. Wozniak et al. (Eds)., WMNC 2009, IFIP AICT 308, pp. 359-369, 2009.

(C) IFIP International Federation for Information Processing (2009).

[19] "Vertical Handoff Decision using Game Theory Approach for Multi-mode Mobile Terminals in Next Generation Wireless Networks", - International Journal of Computer Applications (0975 - 8887) Volume 36-No.11, December 201131

[20] "Quality Dependent Vertical Handover Decision Algorithm for Fourth Generation(4G) Heterogeneous Wireless Networks", - Nikhil Patel, Kiran Parmar, IJCEM International Journal of Computational Engineering \& Management, Vol. 15 Issue 2, March 2012.

[21] "SMIRT with Call Admission Control (CAC) Based Vertical Handover Decision for Seamless Mobility in Multi-Access 4G Heterogeneous Wireless Overlay Networks", - P.Vetrivelan and P.Narayanasamy, IMECS (2012), Hong Kong.

\section{Authors Profile}

A. Bhuvaneswari completed her Masters Degree in Computer Science and Master of Philosophy in Computer Science in the years 2002 and 2005 respectively. She has 10 years of teaching experience at Cauvery College for Women , Trichy, Tamil Nadu, India. Currently she is doing her research in the area of Mobile Communication under the guidance of Dr.E.George Dharma Prakash Raj . 
Dr.E. George Dharma Prakash Raj completed his Masters Degree in Computer Science and Masters of Philosophy in Computer Science in the years 1990 and 1998. He has also completed his Doctorate in Computer Science in the year 2008. He has around twenty-one years of Academic experience and thirteen years of Research experience in the field of Computer Science. Currently he is working as an Asst.Professor in the Department of Computer Science and Engineering at Bharathidasan University, Trichy, India. He has published several papers in International Journals and Conferences related to Computer Science and has been an Editorial Board Member, Reviewer and International Programme Committee Member in many International Journals and Conferences. He has convened many National and International Conferences related to Computer Science. 